\title{
Eosinophilic Granulomatous Polyangitis with Renal Granulomatous Angitis and Interstitial Eosinophilic Infiltration without Lung Granuloma
}

\author{
Shinya Kawamoto ${ }^{1^{*}}$, Hideo Misawa ${ }^{1}$, Katsuhiro Nagahori ${ }^{1}$, Shigeyuki Ota ${ }^{1}$, Atsushi Kitazawa ${ }^{1}$, Atsunori Yoshino ${ }^{1}$, Tetsuro Takeda ${ }^{1}$ and Yoshihiko Ueda $^{2}$
}

${ }^{1}$ Department of Nephrology, Dokkyo Medical University Koshigaya Hospital, Japan

${ }^{2}$ Department of Pathology, Dokkyo Medical University Koshigaya Hospital, Japan

"Corresponding author: Shinya Kawamoto, Department of Nephrology, Dokkyo Medical University Koshigaya Hospital, 343-8551, 2-1-50 Minamikoshigaya Koshigaya Saitama, 343-8555, Japan, Tel: 048-965-1111; Fax: 048-965-1372; E-mail: kwmt@dokkyomed.ac.jp

Received date: November 13, 2016; Accepted date: November 17, 2016; Published date: November 20, 2016

Copyright: @ 2016 Kawamoto S, et al. This is an open-access article distributed under the terms of the Creative Commons Attribution License, which permits unrestricted use, distribution, and reproduction in any medium, provided the original author and source are credited.

\begin{abstract}
Eosinophilic granulomatous with polyangiitis (EGPA) is systemic vasculitis characterized by concomitant symptoms of asthma, allergic rhinitis, and marked increase in peripheral eosinophilia. It was previously known as Churg-Strauss syndrome. EGPA incidence in Japan is very low, with only approximately 1,800 cases reported. Renal involvement occurs in approximately $20-25 \%$ of EGPA patients, and the most typical expression is pauciimmune crescentic glomerulonephritis. We herein report a case of 69-year-old Japanese woman with fever and high titer of myeloperoxidase-antineutrophil cytoplasmic antibodies (MPO-ANCA) and eosinophilia. Her renal biopsy showed massive interstitial nephritis with granulomatous vasculitis like lesion without apparent active crescent formation in glomeruli.
\end{abstract}

Immediately after steroid treatment (prednisolone [PSL] $30 \mathrm{mg} /$ day), she had symptomatic relief and was discharged with a reduction in MPO-ANCA.

Keywords: EGPA;

Granulomatous angitis

\section{Introduction}

Eosinophilic granulomatosis with polyangiitis (EGPA) is a multisystemic disorder involving small vessel antineutrophil cytoplasmic antibody (ANCA)-associated vasculitis, which is defined as an eosinophil-rich and necrotizing granulomatous inflammation often involving the respiratory tract, and necrotizing vasculitis predominantly affecting small to medium vessels, which is associated with asthma and eosinophilia. Formerly known as Churg-Strauss syndrome, this eponym was replaced during the 2012 Revised International Chapel Hill consensus conference (CHCC) with the aim of focusing on the histopathology of the disease [1,2]. Unlike the 1990 American College of Rheumatology classification criteria and the former CHCC classification criteria, the 2012 CHCC reported for the first time that ANCA is found in EGPA, especially in patients with glomerulonephritis.

EGPA incidence in Japan is reported to be approximately 100 new cases annually, and the total number of EGPA patients was approximately 1,886 cases in 2008 [3]. EGPA incidence in Europe is 0.5-6.8 new cases per year per 1 million of the population, whereas its prevalence is $10.7-13$ cases per 1 million of the population. It mostly affects individuals between 40 and 60 years old, and the mean age at diagnosis is 48 years [4].

We report one case of EGPA with renal granulomatous lesion, which is less frequent than EGPA with crescentic glomerulonephritis.

\section{Case Report}

A 69-year-old woman had a more than 40-year history of chronic sinusitis, allergic rhinitis, and diabetes mellitus, a 14-year history of bronchiectasis, and a history of autoimmune hemolytic anemia treated with corticosteroids 10 years previously that remained in remission with $5 \mathrm{mg}$ of prednisolone. She had no family history of renal disease or dialysis.

She had a fever 1 month previously and was treated with antibiotics (clarithromycin $[\mathrm{CAM}]$ ) for infectious disease). However, her symptoms did not show any improvement with CAM, and she developed fever, arthralgia, and myalgia within 2 weeks prior to admission despite a change in antibiotics to levofloxacin (LVFX).

Test results for myeloperoxidase-antineutrophil cytoplasmic antibodies (MPO-ANCA) $(288 \mathrm{U} / \mathrm{ml})$, proteinuria, and urine occult blood were positive, and LVFX did not result in improvement; therefore, she was referred to our hospital for further evaluation and treatment. On physical examination, her temperature was $37.5^{\circ} \mathrm{C}$ and her blood pressure was $141 / 74 \mathrm{mmHg}$. Lower extremity edema without dyspnea was evident. She was prescribed bed rest without activity.

Chest radiography revealed mild cardiac enlargement, with a cardiothoracic ratio of $56 \%$ without pleural effusions; chest computed tomography revealed no granulomatous lesion (Figure 1). 
Citation: Kawamoto S, Misawa H, Nagahori K, Ota S, Kitazawa A, et al. (2016) Eosinophilic Granulomatous Polyangitis with Renal Granulomatous Angitis and Interstitial Eosinophilic Infiltration without Lung Granuloma. J Nephrol Ther 6: 267. doi: 10.4172/2161-0959.1000267

Page 2 of 4
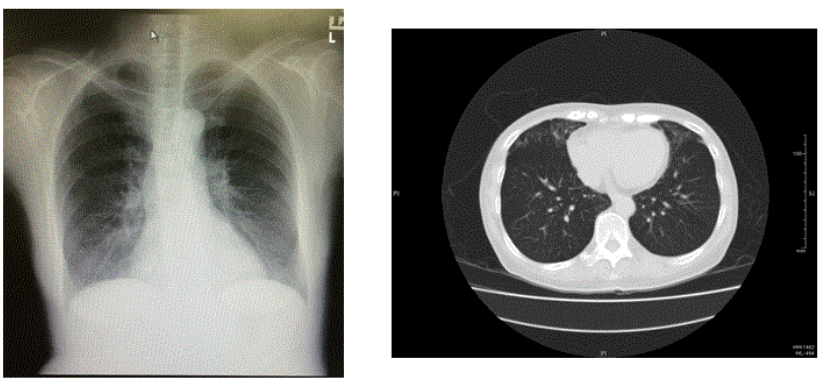

Figure 1: X-ray and Computed tomography (CT) of the chest. Chest radiography revealed mild cardiac enlargement as CTR 56\% without pleural effusions, and a chest computed tomography (CT) scan revealed no granulomatous lesion in lung.

The following laboratory results were obtained (Table 1): white blood cell (WBC) count, 14,100 WBC/ $\mu$ l eosinophil $1410 / \mu \mathrm{l}(10 \%$ of
WBC); red blood cell (RBC) count, $328 \times 104 \mathrm{RBC} / \mu \mathrm{l}$; hemoglobin, 9.5 $\mathrm{g} / \mathrm{dl}$; hematocrit, 28.8\%; platelet count (plt), $37.3 \times 104 \mathrm{plt} / \mu \mathrm{l}$; total protein, $5.8 \mathrm{~g} / \mathrm{dl}$; albumin, $2.19 \mathrm{~g} / \mathrm{dl}$; blood urea nitrogen, $14 \mathrm{mg} / \mathrm{dl}$; serum creatinine $(\mathrm{Cr}), 0.8 \mathrm{mg} / \mathrm{dl}$; sodium, $130 \mathrm{mEq} / \mathrm{L}$; potassium, 3.8 $\mathrm{mEq} / \mathrm{L}$; chloride, $96 \mathrm{mEq} / \mathrm{L}$; C-reactive protein (CRP), $10.95 \mathrm{mg} / \mathrm{dl}$; plasma glucose, $118 \mathrm{mg} / \mathrm{dl}$; hemoglobin A1c, 8.1\%; aspartate aminotransferase, $15 \mathrm{IU} / \mathrm{L}$; alanine aminotransferase, $10 \mathrm{IU} / \mathrm{L}$; alkaline phosphatase, $172 \mathrm{IU} / \mathrm{L}$; gamma glutamyl transpeptidase, $24 \mathrm{IU} / \mathrm{L}$; IgG, 1,490 mg/dl; IgM, $153 \mathrm{mg} / \mathrm{dl}$; IgA, $227 \mathrm{mg} / \mathrm{dl}$ and IgE, $728 \mathrm{IU} / \mathrm{ml}$. The third complement component (C3) level was $144 \mathrm{mg} / \mathrm{dl}$ (normal, $50-130 \mathrm{mg} / \mathrm{dl}$ ); the fourth component (C4) level was $16.5 \mathrm{mg} / \mathrm{dl}$ (normal, $10-50 \mathrm{mg} / \mathrm{dl}$ ). Hemolytic complement activity via the classical pathway (CH50) was $42.2 \mathrm{U} / \mathrm{ml}$ (normal, 25.0-48.0 U/ml) and test results for antinuclear antibody were negative. MPO antibodies were $>$ $300 \mathrm{U} / \mathrm{ml}$, and proteinase 3 antibodies (PR3), ANCA, and antiglomerular basement membrane (anti-GBM) antibodies were not detected. Urinalysis showed $0.65 \mathrm{~g}$ of protein per $1 \mathrm{gram}$ of $\mathrm{Cr}$ and 10-29 RBC per high-power field (HPF). The urinary $\beta-2$ microglobulin level was $1,539 \mathrm{ng} / \mathrm{ml}$.

\begin{tabular}{|c|c|c|c|c|c|}
\hline \multicolumn{2}{|l|}{ CBC } & \multicolumn{2}{|c|}{ WBC differentiation } & \multirow{2}{*}{$\begin{array}{l}\text { TP } \\
\text { Alb }\end{array}$} & \multirow{2}{*}{$\begin{array}{l}5.8 \mathrm{mg} / \mathrm{dl} \\
2.19 \mathrm{mg} / \mathrm{dl}\end{array}$} \\
\hline WBC & $14100 / \mu \mathrm{l}$ & Polys & $77.50 \%$ & & \\
\hline RBC & $328 \times 104 / \mu l$ & Lympho & $7 \%$ & CRP & $10.95 \mathrm{mg} / \mathrm{dl}$ \\
\hline $\mathrm{Hgb}$ & $9.5 \mathrm{~g} / \mathrm{dl}$ & Mono & $4.50 \%$ & \multicolumn{2}{|c|}{ Immunological findings } \\
\hline Hct & $28.80 \%$ & Eosino & $10 \%$ & HBAg & \\
\hline PIt & $37.3 \times 104 / \mu l$ & Baso & $1 \%$ & HCV Ab & \\
\hline \multicolumn{2}{|l|}{ Urine } & \multicolumn{2}{|c|}{ Chemistry } & TPHA & \\
\hline $\mathrm{pH}$ & 5.5 & T-Bil & $0.52 \mathrm{mg} / \mathrm{dl}$ & $\lg G$ & $1490 \mathrm{mg} / \mathrm{dl}$ \\
\hline SG & 1.029 & AST & $15 \mathrm{mg} / \mathrm{dl}$ & $\lg A$ & $227 \mathrm{mg} / \mathrm{dl}$ \\
\hline \multirow[t]{2}{*}{ Protein } & $3+$ & ALT & $10 \mathrm{IU} / \mathrm{I}$ & $\lg M$ & $153 \mathrm{mg} / \mathrm{dl}$ \\
\hline & $0.65 \mathrm{~g} / \mathrm{gCr}$ & ALP & $172 \mathrm{IU} / \mathrm{I}$ & $\lg \mathrm{E}$ & $728 \mathrm{mg} / \mathrm{dl}$ \\
\hline Occult blood & $3+$ & LDH & $161 \mathrm{IU} / \mathrm{I}$ & C3 & $144 \mathrm{mg} / \mathrm{dl}$ \\
\hline Glucose & $1+$ & $\mathrm{Na}$ & $130 \mathrm{IU} / \mathrm{I}$ & $\mathrm{C} 4$ & $16.5 \mathrm{mg} / \mathrm{dl}$ \\
\hline Keton & - & $\mathrm{K}$ & $3.8 \mathrm{mEq} / \mathrm{l}$ & $\mathrm{CH} 50$ & $42.2 \mathrm{IU} / \mathrm{ml}$ \\
\hline$\beta 2 M G$ & $1539.3 \mathrm{ng} / \mathrm{ml}$ & $\mathrm{Cl}$ & $96 \mathrm{mEq} / \mathrm{l}$ & P-ANCA & $300 \mathrm{U} / \mathrm{ml}$ \\
\hline Urine sediment & & $\mathrm{Ca}$ & $8.1 \mathrm{mEq} / \mathrm{l}$ & C-ANCA & $1 \mathrm{U} / \mathrm{ml}$ \\
\hline RBC & 73 & $P$ & $2.4 \mathrm{mg} / \mathrm{dl}$ & ANA & \\
\hline \multirow[t]{3}{*}{ WBC } & 52 & BUN & 14 mg/dl & & \\
\hline & & Cre & $0.8 \mathrm{mg} / \mathrm{dl}$ & & \\
\hline & & UA & $2.1 \mathrm{mg} / \mathrm{dl}$ & & \\
\hline
\end{tabular}

Table 1: Laboratory findings on admission.

A percutaneous renal biopsy was performed on day 2 (Figures 2a-2d). Widely tubular atrophy and diffuse infiltration of numerous eosinophils (Figure $2 \mathrm{~b}$ arrowhead), neutrophils and lymphocytes were noted in interstitium, surrounding the granulomatous lesion (Figure 2a arrowhead). Furthermore, granulomatous vasculitis like lesion with histiocytes and lymphocytes around the interlobular artery were also observed in Periodic acid-silver methenamine stain (PAM) stain and Masson trichrome stain (Figures $2 \mathrm{c}$ and $2 \mathrm{~d}$ ). Fibrinoid necrosis of the 
Citation: Kawamoto S, Misawa H, Nagahori K, Ota S, Kitazawa A, et al. (2016) Eosinophilic Granulomatous Polyangitis with Renal Granulomatous Angitis and Interstitial Eosinophilic Infiltration without Lung Granuloma. J Nephrol Ther 6: 267. doi: 10.4172/2161-0959.1000267

Page 3 of 4

interlobular artery was also observed in the center of granulomatous lesion and so this granuloma was originated from an interlobular artery (Figure 2d). Of 10 glomeruli, six were globally sclerotic, two showed mesangial proliferation and other glomeruli were essentially normal without apparent active crescent formation. This global sclerosis was thought to be consistent with her age and long term usage of corticosteroid.
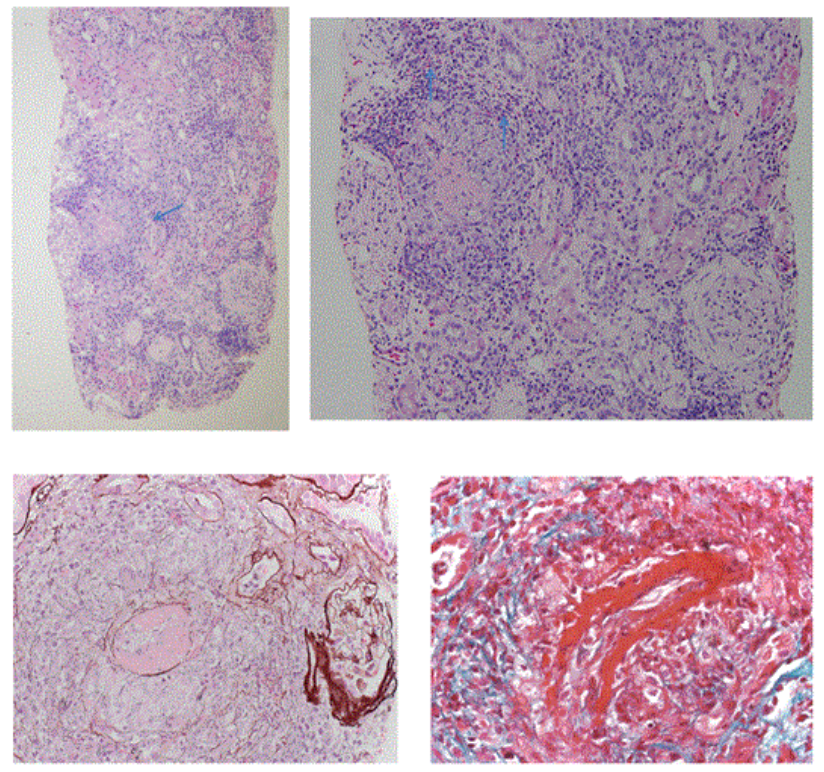

Figure 2: Renal biopsy findings. 2a: Hematoxylin-Eosin (HE) stain; magnification 40X. Light microscopy images show widely tubular atrophy and massive infiltration of eosinophils, neutrophils, and lymphocytes were seen in tubulointerstitial lesion. Granulomatous formation (arrowhead) near the glomerulus was observed. Of 10 glomeruli, six were globally sclerotic, two showed mesangial proliferation and other glomeruli were essentially normal without apparent active crescent formation. 2b: Hematoxylin-Eosin (HE) stain; magnification 100X. Diffuse infiltration of numerous eosinophils (arrowhead), neutrophils, and lymphocytes were seen in interstitium surrounding the granulomatous lesion. 2c: Periodic acid-silver methenamine (PAM) stains: original magnification 400X. Black staining in basement membrane of vascular smooth cells revealed that this granuloma originated from an interlobular artery. 2d: Masson trichrome stain: original magnification 600X. Fibrinoid necrosis of the interlobular artery was observed in the center of the granulomatous lesion.

There were no remarkable glomerular changes except for global sclerosis. Immuno-deposits of IgG, IgA, IgM, C1q, C3, and fibrinogen were absent.

Our patient was diagnosed as having definite EGPA because of the three main clinical findings (allergic rhinitis, eosinophilia and fever, myalgia and muscle weakness) and the histological finding (granulomatosis with eosinophilic infiltration around arteriole with fibrinoid necrosis) according to the diagnostic criteria of EGPA by Ministry of health and welfare in Japan.

She was treated with corticosteroids (PSL $30 \mathrm{mg}$ /day) (Figure 3).

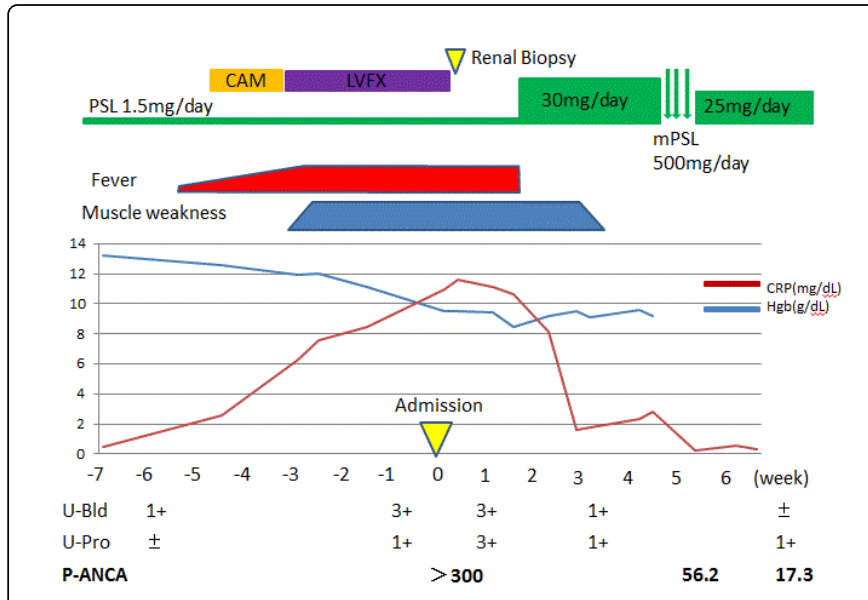

Figure 3: Clinical course. 6 weeks prior to admission, her examination showed normal range of CRP, urinary protein $(+)$, urinary occult blood $( \pm)$. One month prior to admission, she showed antibiotics resistant fever and muscle weakness with gradually elevated CRP and anemia. After admission, she was diagnosed as EGPA by real biopsy and treated by corticosteroid therapy. After treatment with oral predonisolone at initial dose of $30 \mathrm{mg}$, hematuria, vasculitic symptoms were dramatically improved. She was discharged after PSL tapered.

Immediately after PSL administration, she had a normalized serum CRP level and showed dramatic symptomatic relief of her fever, arthralgia, muscle weakness, and myalgia. Anemia, proteinuria, and urine occult blood improved. PSL was tapered to $25 \mathrm{mg} /$ day after 4 weeks, and she was discharged with a reduction in MPO-ANCA (17.3 $\mathrm{U} / \mathrm{ml})$.

\section{Discussion}

EGPA typically develops into three sequential phases marked by a progression of the main symptoms. The first phase, also called allergic, is most common during the second or third decade of life and is distinguished by asthma, allergic rhinitis, and sinusitis. Subsequently, the eosinophilic phase develops. The main pathological findings of this phase are increased peripheral eosinophilic count and eosinophilic organ infiltrations, especially in the lungs, heart, and gastrointestinal system. The third phase is vasculitic. During this last phase, the patient experiences the consequences of necrotizing vasculitis (e.g., peripheral neuropathy, crescentic glomerulonephritis), which is generally associated with vascular or extravascular granulomatosis, and constitutional symptoms like fever, malaise, and weight loss [5]. In this case, the woman had a history of allergic rhinitis since her second decade of life, which is a symptom of the first (allergic) phase.

ANCA is present in approximately $40-60 \%$ of patients; perinuclear ANCA is the prevalent pattern with antibody specificity for anti-MPO $[5,6,7]$.

Recently, it was reported by Sablé-Fourtassou et al. [8] that ANCApositive EGPA patients, compared with ANCA-negative patients, more frequently had kidney involvement ( $35 \%$ vs. $4 \%$ ). Comarmond also reported the same results for a cohort of 383 in the French Vasculitis Study Group [9]. Although less frequent than the other two types of ANCA-associated vasculitis (AAVs) (microscopic polyangiitis [mPA] 
Citation: Kawamoto S, Misawa H, Nagahori K, Ota S, Kitazawa A, et al. (2016) Eosinophilic Granulomatous Polyangitis with Renal Granulomatous Angitis and Interstitial Eosinophilic Infiltration without Lung Granuloma. J Nephrol Ther 6: 267. doi: 10.4172/2161-0959.1000267

Page 4 of 4

and granulomatosis with polyangiitis), renal involvement occurs in approximately $25 \%$ of EGPA patients; the most typical expression is pauci-immune crescentic glomerulonephritis, which has clinical features ranging from isolated urinary abnormalities (proteinuria, hematuria) to rapidly progressive glomerulonephritis [6]. Moosig also reported that renal involvement occurred in $18 \%$ of 150 monocentric cases in Germany [10]. It is suspected that MPO-ANCA induces abundant proinflammatory cytokines in EGPA as well as in mPA [11]. Our patient had an extremely high P-ANCA titer $(>300 \mathrm{U} / \mathrm{ml})$ and renal involvement, which is consistent with previous reports. Her renal involvement included urinary abnormalities (proteinuria, hematuria) without $\mathrm{Cr}$ level elevation $(0.8 \mathrm{mg} / \mathrm{dl})$. Renal biopsy results revealed granulomatous changes, histiocytes and lymphocytes around the necrotizing interlobular artery, and massive interstitial infiltration of eosinophils and lymphocytes without apparent active crescent formation in glomeruli, which could be explained by renal involvement. Regarding renal granulomatous changes in EGPA, these are less commonly accompanied by crescent formation. Bajema reported that only 16 out of 157 systemic vasculitis patients showed renal granulomatous lesions; among these 16 patients, only two had EGPA [12]. We found only one case report of renal granulomatous lesions in EGPA [13]. In EGPA, lung granuloma is well known, but it may be accompanied by granulomatous lesions in the kidney.

We report a rare case of EGPA with renal granulomatous lesions and eosinophilic infiltration without crescent formation, respiratory symptoms, or lung granuloma. Necrotizing vasculitis as the renal involvement and lung granuloma as the respiratory involvement in EGPA are well known, but EGPA may be accompanied by granulomatous lesions in the kidney.

\section{Compliance with Ethical Standards}

This article does not include a research involving human participants which needs the informed consent or animal which needs the statement on welfare of animals.

\section{Conflict of Interest}

All the authors have declared that no conflict of interest exists.

\section{References}

1. Jennette JC, Falk RJ, Bacon PA, Basu N, Cid MC, et al. (2013) 2012 Revised international Chapel Hill consensus conference nomenclature of vasculitis. Arthritis Rheum 65: 1-11.
2. Gioffredi A, Maritani F, Oliva E, Buzio C (2014) Eosinophilic granulomatosis with polyangitis: An overview. Front immunol 5: 549.

3. Sada KE, Amano K, Uehara R, Yamamura M, Arimura Y, et al. (2014) Research Committee on Intractable Vasculitides, the Ministry of Health, Labour, Welfare of Japan. A nationwide survey on the epidemiology and clinical features of eosinophilic granulomatosis with polyangiitis (ChurgStrauss) in Japan. Mod Rheumatol 24: 640-644.

4. Mouthon L, Dunogue B, Guillevin L (2014) Diagnosis and classification of eosinophilic granulomatosis with polyangitis (formerely named Churg-Strauss syndrome). J Autoimmun 48-49: 99-103.

5. Pagnoux C, Guilpain P, Guillevin L (2007) Churg-Strauss syndrome. Curr Opin Rheumatol 19: 25-32.

6. Sinico RA, Di Toma L, Maggiore U, Tosoni C, Bottero P, et al. (2006) Renal involvement in Churg-Strauss syndrome. Am J Kidney Dis 47: 770-779.

7. Sinico RA, Di Toma L, Maggiore U, Bottero P, Radice A, et al. (2005) Prevalence and clinical significance of antineutrophil cytoplasmic antibodies in Churg-Strauss syndrome. Arthritis Rheum 52: 2926-2935.

8. Sablé-Fourtassou R, Cohen P, Mahr A, Pagnoux C, Mouthon L, et al. (2005) Antineutrophil cytoplasmic antibodies and the Churg-Strauss syndrome. Ann Intern Med 143: 632-638.

9. Comarmond C, Pagnoux C, Khellaf M, Cordier JF, Hamidou M, et al. (2013) Eosinophilic granulomatosis with polyangiitis (Churg-Strauss): clinical characteristics and long-term followup of the 383 patients enrolled in the French Vasculitis Study Group cohort. Arthritis Rheum 65: 270-281.

10. Moosig F, Bremer JP, Hellmich B, Holle JU, Holl-Ulrich K, et al. (2013) A vasculitis centre based management strategy leads to improved outcome in eosinophilic granulomatosis and polyangiitis (Churg-Strauss, EGPA): monocentric experiences in 150 patients. Ann Rheum Dis 72: 1011-1017.

11. Hellmich B, Csernok E, Gross WL (2005) Proinflammatory cytokines and autoimmunity in Churg-Strauss syndrome. Ann N Y Acad Sci 1051: 121-131.

12. IM Bajema, EC Hagen, F Ferrario (1997) Renal granulomas in systemic vasculitis. Clinical Nephrology 48: 16-21.

13. Kanda T, Tanio H, Wu C, Nishihara H, Nogaki F, et al. (2010) ChurgStrauss syndrome with severe granulomatous angitis and crescentic glomerulonephritis, which developed during therapy with a leulotoriene receptor antagonist. Clin Exp Nephrol 14: 602-607. 